\title{
Subcutaneous Delivery of High-Dose/Volume Biologics: Current Status and Prospect for Future Advancements
}

This article was published in the following Dove Press journal: Drug Design, Development and Therapy

\author{
Advait V Badkar' \\ Rajesh B Gandhi ${ }^{2}$ \\ Shawn P Davis ${ }^{3}$ \\ Michael J LaBarre ${ }^{4}$ \\ 'Pharmaceutical Research \& Development, \\ Pfizer Inc., Andover, MA, USA; '²rug \\ Product Science \& Technology, Bristol- \\ Myers Squibb, Co., New Brunswick, NJ, \\ USA; ${ }^{3}$ BioPharmaceuticals Development, \\ Research \& Development, AstraZeneca, \\ Cambridge, MA, UK; ${ }^{4}$ Halozyme \\ Therapeutics, Inc., San Diego, CA, USA
}

Correspondence: Advait V Badkar 68 Lowell Junction Road (K2030),

Andover, MA 01810, USA

Tel +|-3|4-677-406|

Email advait.v.badkar@pfizer.com

\begin{abstract}
Subcutaneous (SC) delivery of biologics has traditionally been limited to fluid volumes of 1-2 $\mathrm{mL}$, with recent increases to volumes of about $3 \mathrm{~mL}$. This injection volume limitation poses challenges for high-dose biologics, as these formulations may also require increased solution concentration in many cases, resulting in high viscosities which can affect the stability, manufacturability, and delivery/administration of therapeutic drugs. Currently, there are technologies that can help to overcome these challenges and facilitate the delivery of larger amounts of drug through the SC route. This can be achieved either by enabling biologic molecules to be formulated or delivered as high-concentration injectables $(>100 \mathrm{mg} / \mathrm{mL}$ for antibodies) or through facilitating the delivery of larger volumes of fluid ( $>3 \mathrm{~mL}$ ). The SC Drug Delivery and Development Consortium, which was established in 2018, aims to identify and address critical gaps and issues in the SC delivery of high-dose/volume products to help expand this delivery landscape. Identified as a high priority out of the Consortium's eight problem statements, it highlights the need to shift perceptions of the capabilities of technologies that enable the SC delivery of large-volume $(>3 \mathrm{~mL})$ and/or high-dose biologics. The Consortium emphasizes a patient-focused approach towards the adoption of SC delivery of large-volume/high-concentration dosing products to facilitate the continued expansion of the capabilities of novel SC technologies. To raise awareness of the critical issues and gaps in highdose/volume SC drug development, this review article provides a generalized overview of currently available and emerging technologies and devices that could facilitate SC delivery of high-dose/volume drug formulations. In addition, it discusses the challenges, gaps, and future outlook in high-dose/volume SC delivery as well as potential solutions to exploit the full value of the SC route of administration.
\end{abstract}

Keywords: high-dose biologic, drug delivery technologies, subcutaneous drug delivery, intravenous drug delivery, patient preference, large-volume subcutaneous delivery

\section{Introduction}

Biologics are a rapidly growing class of innovative treatments for many serious diseases, such as cancer, metabolic disorders, cardiovascular conditions, genetic disorders, and immunological diseases. ${ }^{1,2}$ In contrast to synthetic small molecule drugs, administration of efficacious doses of biologic agents is challenging due to their intrinsic nature, including high molecular weight, physical and chemical instability, and susceptibility to enzymatic degradation. Historically, most biologics by default have been administered to patients parenterally, via the intravenous (IV) route. While this is the quickest way to achieve desired drug levels in the blood 
with $100 \%$ drug bioavailability by definition, the IV route typically requires the services of a trained healthcare professional (HCP) for administration. As a result, the patient and/or caregiver must make appointments and visit the clinic in person which is time-consuming, inconvenient, and often uncomfortable for patients who are being treated for disorders requiring long-term and frequent administration. This increases treatment burden and adds to the overall cost of healthcare. ${ }^{3,4}$ With a longer life span expected to translate to a growing number of patients diagnosed with chronic conditions, this trend has important financial implications for overall healthcare resource utilization.

Self- or caregiver-assisted administration options have generated keen interest in recent years. In an effort to improve patient adherence, reduce treatment burden, increase convenience and decrease treatment cost, approaches to the systemic delivery of biologics are increasingly becoming patientcentric. ${ }^{2,4}$ Moreover, the US Food and Drug Administration (FDA) is currently working on a patient-focused initiative that would ensure that the patient's voice and experiences are captured and meaningfully incorporated into the drug development and evaluation processes. ${ }^{5}$ Subcutaneous (SC) delivery as an alternative to IV infusion is of increasing interest as it provides expanded opportunity for self- or caregiver-assisted administration at home or in an office setting (using devices such as prefilled syringes, autoinjectors, wearable bolus injectors and pumps) and reduces the frequency of or eliminates hospital visits, thereby improving patient experience and increasing patient compliance, ${ }^{6-9}$ reducing patient and caregiver treatment burden, and lowering treatment costs and healthcare resource utilization. ${ }^{10-19}$ Additionally, there are a number of reports available in the literature that indicate switching to SC administration may reduce instances of infusion-related reactions often associated with IV infusions. ${ }^{20-22}$ Other promising patient-centric approaches that have been studied for sub/transcutaneous self-administration of biologics include microneedles, ${ }^{23,24}$ microneedle patches, ${ }^{25}$ jet/needlefree injections, ${ }^{26}$ and SC implants. ${ }^{27}$

While significant progress has been made in SC drug development and delivery, there are still several challenges that need to be addressed to exploit the full value of the SC route of administration. The SC Drug Delivery and Development Consortium, which was convened in 2018, aims to identify and raise awareness of these challenges in the SC industry through open information and knowledge sharing among pharmaceutical industry experts in a precompetitive environment. Further details of the Consortium's mission and objectives, as well as an overview of the eight problem statements developed by the Consortium to highlight actionable issues in the SC industry, are described in their publication. ${ }^{28}$ The current article focuses on one of these problem statements regarding the development of technologies that enable the SC delivery of high-dose and/or largevolume biologics.

Whereas IV delivery can administer large volumes of medication directly into the bloodstream without volume limitation, SC injections have traditionally been limited to fluid volumes of $1-2 \mathrm{~mL}$, with recent increases to volumes of about $3 \mathrm{~mL}^{29}$ This "traditional" volume limitation for SC injection was due to the restrictions of the extracellular matrix in the SC space. $^{30,31}$ In the case of biologics, the traditional injection volume limitation poses additional challenges for formulation development. Many biologic molecules have an exponential relationship between concentration and viscosity, ${ }^{32}$ and the traditional volume limitation of $1-2 \mathrm{~mL}$ may require increased solution concentrations to allow for SC delivery of high doses. This can result in very high viscosities, and affect the stability, manufacturability, and delivery/administration of the therapeutic drugs. ${ }^{33}$ Currently, there are technologies that enable the delivery of higher amounts of drug through the $\mathrm{SC}$ route, either by (1) enabling biologic molecules to be formulated and delivered as high-concentration injectables $(>100 \mathrm{mg} / \mathrm{mL}$ for antibodies) or (2) facilitating the SC delivery of larger volumes of fluid $(>3 \mathrm{~mL}$ ) using innovative devices or by locally and transiently modifying the SC space. In this article, as part of the work of the SC Drug Delivery and Development Consortium, we aim to shift perceptions of the capabilities of these innovative technologies to advance the field of SC drug delivery and development. As such, we provide an overview of the aforementioned technologies and devices that are currently available or in clinical development, and explore physical and chemical characteristics of both the drug product (eg, viscosity, volume) as well as the device (eg, applied force, infusion time) and their interplay in achieving high-dose/volume delivery. Additionally, we will also discuss the challenges, gaps, and future outlook in high-dose/volume SC delivery as well as potential solutions to exploit the full value of the SC route of administration to meet current patient needs.

In Figure 1, we provide a generalized depiction of the current landscape of technologies and devices that facilitate the SC delivery of large-volume (typically $>3-25 \mathrm{~mL}$ but as high as $600 \mathrm{~mL}$ ) and high-dose biologics in a home, office, or clinical/infusion center. As this is a generalized depiction, we acknowledge that there are outliers that are not captured in the illustration or discussions. This review is intended to provide a generalized overview of the field and is not 


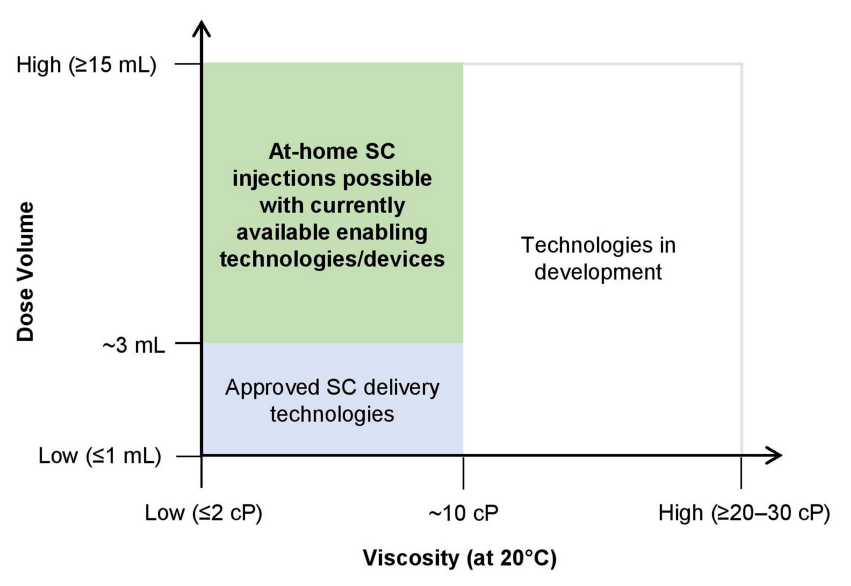

Figure I Overview of the current technology/device landscape to facilitate the subcutaneous (SC) delivery of large-volume (typically $>3-25 \mathrm{~mL}$ but as high as $600 \mathrm{~mL}$ ) and high-dose biologics in a home, office, or clinical/infusion center.

aimed to be all inclusive. Also in this regard, as we focus on SC delivery of high-dose/volume biologics, we do not describe all technologies that enable SC drug delivery such as microneedles which currently do not provide adequate drug loads to meet this criteria. The authors also acknowledge that high dose/volume SC deliveries can be accomplished with large bore needles or long infusion times but have chosen to focus this discussion on patient-preferred solutions. Similarly, molecular engineering approaches to impact the properties of the drug product are not considered as part of this review. The approach of each development organization may vary based on their relative strengths and their intended patient population.

\section{Overview of Current and Novel Technologies Facilitating SC Administration of High-Dose/ Volume Biologics}

Currently, there are a number of technologies that facilitate SC delivery of high doses or larger volumes of biologics. Technologies, which will be discussed below, include a) those that enable the formulation of high-dose/concentration SC injectables, or b) devices that enable the SC administration of higher concentrations/viscosities or larger volumes of fluid or c) those that modify the SC space to facilitate the delivery of a larger volume of fluid.

\section{Formulation Technologies Enabling SC Delivery of High-Dose Biologics}

Formulation technologies that enable SC delivery of highdose/concentration injectables focus on protecting the drug product and formulations from issues associated with high concentration/viscosity. These issues may include molecular crowding leading to physical instability (unfolding, aggregation, particle formation), or modifying ionic and hydrophobic interactions to lower viscosity of highconcentration formulations, impacting overall physical and chemical stability over shelf-life, etc. ${ }^{33-36}$

Some formulation technologies, such as the proprietary Xeriject $^{\mathrm{TM}}$ non-aqueous formulation technology (Table 1), allow for high-concentration formulation by creating a suspension in a carrier fluid. Multiple other technologies are in the pre-clinical stages of development to achieve similar goals (Table 1), including Elektroject ${ }^{\mathrm{TM}}$, the Microglassification $^{\mathrm{TM}}$ technology, and the Crystalomics ${ }^{\circledR}$ drug delivery technology. These technologies enable the formulation of high-concentration fluids via the formation of microparticles, microbeads, and crystals, respectively, for $\mathrm{SC}$ injection (Table 1).

Other technologies in development allow for highconcentration formulation with lower, more manageable viscosity by minimizing intermolecular interactions in solution (Table 1). The Arestat ${ }^{\mathrm{TM}}$ technology (Table 1) is utilized in formulations of ultra-rapid acting insulin (currently in Phase 2 clinical trials), ultra-concentrated rapidacting insulin (up to $1000 \mathrm{U} / \mathrm{mL}$, currently in Phase 1 clinical trials), as well as other products in earlier stages of development. ${ }^{37}$ The BioChaperone ${ }^{\circledR}$ platform technology (Table 1) has been utilized in the development of two ultra-rapid formulations of insulin analog lispro (BioChaperone ${ }^{\circledR}$ Lispro), and has been tested in Phase 1 and 2 clinical trials for type 1 and type 2 diabetes across multiple insulin delivery devices with successful glycemic control; ${ }^{38}$ Phase 3 trials are soon to be launched. ${ }^{38}$ Additionally, the EXCELSE ${ }^{\mathrm{TM}}$ high-concentration formulation technology (Table 1) is utilized in formulations of trastuzumab, rituximab, and infliximab (all of which are currently in proof-of-concept studies). ${ }^{39}$ In addition to the above-mentioned technologies, there are other formulation tools that are used in industry to manage high viscosity or to lower viscosity of high-concentration solutions (eg, salts, amino acids, and other excipients).

\section{Device Technologies for SC Delivery of High-Dose/Volume Biologics}

Traditionally, syringes and later prefilled syringes, available in various sizes and materials of construction, have been used to deliver volumes of $1-2 \mathrm{~mL}$ of solutions with 
Table I Formulation and Device Technologies Enabling SC Delivery of High-Dose Biologics

\begin{tabular}{|c|c|c|c|}
\hline Type & Technology (Manufacturer) & Key Features & References \\
\hline \multirow[t]{4}{*}{$\begin{array}{l}\text { Formulation technologies that } \\
\text { form fluid suspensions }\end{array}$} & $\begin{array}{l}\text { Xeriject }{ }^{T M} \text { (Xeris Pharmaceuticals, Chicago, } \\
\text { IL, USA) }\end{array}$ & $\begin{array}{l}\text { Uses specialized particle engineering } \\
\text { techniques to create paste formulations }\end{array}$ & {$[40]$} \\
\hline & Elektroject $^{\mathrm{TM}}$ (Elektrofi, Boston, MA, USA) & $\begin{array}{l}\text { Uses a gentle atomization/desiccation } \\
\text { procedure to create microparticles with high } \\
\text { protein loading with improved long term } \\
\text { physical and chemical stability }\end{array}$ & {$[4 I]$} \\
\hline & $\begin{array}{l}\text { Microglassification }{ }^{\mathrm{TM}} \text { (Lindy Biosciences, } \\
\text { Durham, NC, USA) }\end{array}$ & $\begin{array}{l}\text { Enables the dehydration of proteins or other } \\
\text { biologics into stable, spherical microbeads }\end{array}$ & [42] \\
\hline & $\begin{array}{l}\text { Crystalomics }^{\circledR} \text { (Althea/Ajinomoto Bio- } \\
\text { Pharma, San Diego, CA, USA) }\end{array}$ & Creates crystal suspensions & {$[43]$} \\
\hline \multirow{3}{*}{$\begin{array}{l}\text { Formulation technologies that } \\
\text { minimize intermolecular } \\
\text { interactions in solution to reduce } \\
\text { viscosity of high-concentration } \\
\text { formulations }\end{array}$} & Arestat $^{\mathrm{TM}}$ (Arecor, Little Chesterford, UK) & $\begin{array}{l}\text { Uses buffering agents and formulation } \\
\text { excipients to improve protein/peptide } \\
\text { stability in aqueous solutions }\end{array}$ & [44] \\
\hline & BioChaperone ${ }^{\circledR}$ (Adocia, Lyon, France) & $\begin{array}{l}\text { Forms a molecular complex with therapeutic } \\
\text { proteins of interest that improves their } \\
\text { solubility and stability }\end{array}$ & {$[45]$} \\
\hline & $\begin{array}{l}\text { EXCELSE } \\
\text { CA, USA) }\end{array}$ & $\begin{array}{l}\text { Uses a customized amino acid blend that } \\
\text { coats key molecular regions responsible for } \\
\text { the increase in viscosity, thereby preventing } \\
\text { clumping and protein instability }\end{array}$ & {$[46]$} \\
\hline \multirow[t]{7}{*}{$\begin{array}{l}\text { Devices that allow for SC injection } \\
\text { of high viscosity formulations }\end{array}$} & $\begin{array}{l}\text { Safelia }{ }^{\circledR} \text { autoinjector (Nemera, La Verpillière, } \\
\text { France) }\end{array}$ & $\begin{array}{l}\text { Uses a cam system to manage the increased } \\
\text { spring force to deliver I or } 2.25 \mathrm{~mL} \text { fluids of } \\
\text { up to } 1000 \mathrm{cP} \text { viscosity }\end{array}$ & {$[47]$} \\
\hline & $\begin{array}{l}\text { Autoject }{ }^{\circledR} \text { Visco autoinjector (Owen } \\
\text { Mumford, Oxfordshire, UK) }\end{array}$ & $\begin{array}{l}\text { Uses a velocity regulator to minimize shock } \\
\text { and noise }\end{array}$ & {$[48,49]$} \\
\hline & $\begin{array}{l}\text { YpsoMate } 2.25 \text { Pro autoinjector (Ypsomed, } \\
\text { Burgdorf, Switzerland) }\end{array}$ & $\begin{array}{l}\text { Uses a drive system with constant force to } \\
\text { deliver up to } 2.25 \mathrm{~mL} \text { of up to } 50 \mathrm{cP} \text { viscosity }\end{array}$ & {$[50]$} \\
\hline & $\begin{array}{l}\text { Rotaject }^{\circledR} \text { autoinjector (SHL Group, Zug, } \\
\text { Switzerland) }\end{array}$ & $\begin{array}{l}\text { Uses torsion springs and regulators to } \\
\text { control the application of force over time to } \\
\text { deliver I or } 2.25 \mathrm{~mL} \text { fluids of up to several } \\
\text { I00 cP viscosity }\end{array}$ & {$[51]$} \\
\hline & $\begin{array}{l}\text { Vapoursoft }{ }^{\circledR} \text { powered autoinjectors (Bespak, } \\
\text { King's Lynn, UK) }\end{array}$ & $\begin{array}{l}\text { Uses the expansion of a compressed gas to } \\
\text { replace spring force and minimize the impact } \\
\text { on primary containers to deliver I or } \\
2.25 \mathrm{~mL}\end{array}$ & [52] \\
\hline & $\begin{array}{l}\text { AutoTouch }{ }^{\mathrm{TM}} \text { autoinjector (Amgen, } \\
\text { Thousand Oaks, CA, USA) }\end{array}$ & $\begin{array}{l}\text { Uses electromechanical motors to finely } \\
\text { control the application of force over time } \\
\text { and tailor injection rate to patient } \\
\text { preference }\end{array}$ & {$[53,54]$} \\
\hline & $\begin{array}{l}\text { ArQ }{ }^{\circledR} \text {-Bios (Oval Medical Technologies, } \\
\text { Cambridge, UK) }\end{array}$ & $\begin{array}{l}\text { Uses cyclo-olefin co-polymer containers that } \\
\text { are strong enough to withstand the stresses } \\
\text { of delivering } 1 \mathrm{~mL} \text { of a } 1000 \mathrm{cP} \text { fluid in } 5 \\
\text { seconds }\end{array}$ & [55] \\
\hline
\end{tabular}


low viscosity. However, as mentioned previously, the delivery of higher doses in a limited volume may require concentrating the drug product. Technologies to achieve high-concentration formulations either through minimizing aggregation of solutions or suspension of particles in a carrier may result in a consequential increase in the product's viscosity. This in turn may pose delivery challenges, including potential for pain on injection or a requirement for increased force or time to administer the dose. For manual injections, this may impact a patient or caregiver's ability to provide the necessary force to complete the injection with confidence. For automated injections, whether driven by springs or motors, the increased force may result in less desirable design characteristics such as increased size, operation noise, or longer injection times. In extreme cases, the increased force may present a risk of damaging the primary container. $^{56}$

Multiple autoinjector designs have been proposed to manage the increased force necessary for the delivery of high-viscosity fluids with standard $1 \mathrm{~mL}$ or $2.25 \mathrm{~mL}$ prefilled syringes. For autoinjectors with a linear spring providing extrusion force, the most logical approach is to increase the spring force while ensuring the primary container can withstand the increased force through appropriate support, either at the syringe shoulder or flanges. The stresses exerted on the syringe may be both quasi-static as during the extrusion process or a dynamic impulse of energy during the initial release of the spring force and contact with the syringe plunger. Autoinjectors currently in development that use this method to manage the increased force include the Nemera's Safelia ${ }^{\circledR}$ autoinjector platform (Table 1), and the Owen Mumford Autoject ${ }^{\circledR}$ Visco (Table 1). Ypsomed's YpsoMate 2.25 Pro autoinjector (Table 1), currently in development, is the high viscosity alternative to the commercialized YpsoMate 2.25 autoinjector used for fremanezumab (Ajovy $\left.{ }^{\circledR}\right) .{ }^{57}$ In lieu of a linear spring to extrude drug product, several companies have proposed the use of torsion springs and regulators to control the application of force over time. SHL Group's Rotaject ${ }^{\circledR}$ technology (Table 1) was among the first commercialized in $2009 .{ }^{51,58}$ Springs can be avoided altogether if an alternate source of force is applied. Bespak's Vapoursoft ${ }^{\circledR}$ powered autoinjectors, which are in development, use the expansion of a compressed gas to replace spring force (Table 1). Electromechanical motors may also be used to finely control the application of force over time and even tailor injection rate to patient preference. This approach was commercialized by Amgen in their AutoTouch ${ }^{\mathrm{TM}}$ Reusable Autoinjector (Table 1) for etanercept (Enbrel ${ }^{\circledR}$ ) in $2017 .{ }^{54}$ Finally, if the primary container is strong enough to withstand the stresses generated by whichever power source is used, the potential for damage can be minimized. Oval Medical Technologies has used their proprietary cyclo-olefin co-polymer containers in their ArQ ${ }^{\circledR}$-Bios system, currently in development, to manage these stresses (Table 1).

Additionally, device companies have developed several types of innovative needle designs to overcome injectability challenges. Examples include shortened needles, thin wall/ultra-thin wall technology, needles with tapered geometry, side-bores, etc., which enable the delivery of drugs with larger volumes and higher viscosities, and greatly enhance the end-user experience. To address high injection force concerns, butterfly designs, autoinjectors, and needle-free technology ${ }^{59}$ have also been developed. To administer viscous drugs within an acceptable injection time (ideally, no longer than 10 to 15 seconds), short needle technology such as the one developed by BD based on its Neopak ${ }^{\mathrm{TM}} 2.25 \mathrm{~mL}$ glass pre-fillable syringe platform can be utilized. ${ }^{60}$ Additionally, various types of injectable drug-device combination products are currently available for volumes up to $2.25 \mathrm{~mL}$.

An alternative to formulating or delivering biologics at high concentrations (as discussed above) is the ability to inject larger volumes of a formulation via SC delivery. An approach that is being used is the slow SC infusion of a larger volume using wearable devices or on-body delivery systems (OBDS). OBDS allows for the device to be adhered onto the skin (abdomen, upper thigh, upper arm, etc.) using an adhesive. The delivery mechanism that is either mechanical (spring/tension based) or electromechanical is then activated, and allows for needle insertion and injection at a pre-determined/variable delivery rate which minimizes patient discomfort. Volume ranges of 3-100 mL have been delivered for OBDS-based products. ${ }^{61-63}$

There are three large-volume wearable/OBDS injection devices currently licensed that enable SC delivery of volumes $>3 \mathrm{~mL}$ (Table 2). The West SmartDose ${ }^{\circledR} 3.5$ injector (Table 2) is currently on the market as the Repatha (evolocumab) Pushtronex ${ }^{\circledR}$ System. ${ }^{29}$ It is also currently in Phase 3 clinical development with Alexion's ravulizumab-cwvz (Ultomiris ${ }^{\circledR}$ ) for once-weekly SC injection of $100 \mathrm{mg} / \mathrm{mL}^{64}$ The SmartDose ${ }^{\circledR} \quad 10$ injector and SmartDose $^{\circledR} 3.5$ Preloaded injector, which are currently under development, will allow for dose volumes ranging 
Table 2 Device Technologies Enabling SC Delivery of Large-Volume Biologics

\begin{tabular}{|c|c|c|}
\hline Technology (Manufacturer) & Key Features & References \\
\hline $\begin{array}{l}\text { SmartDose }{ }^{\circledR} 3.5 \text { injector (West Pharma, } \\
\text { Exton, PA, USA) }\end{array}$ & $\begin{array}{l}\text { SC delivery of } 3.5 \mathrm{~mL} \text { at a customizable, pre-programmed delivery time } \\
\text { Commercialized }\end{array}$ & {$[67]$} \\
\hline $\begin{array}{l}\text { CRONO ambulatory infusion pumps (Canè } \\
\text { Medical Technology, Rivoli TO, Italy) }\end{array}$ & $\begin{array}{l}\text { Can be worn on elastic belt or collar strap for SC infusions of up to } 100 \mathrm{~mL} \\
\text { Commercialized }\end{array}$ & {$[6 I]$} \\
\hline $\begin{array}{l}\text { Infusion Pump (Sensile Medical, Olten, } \\
\text { Switzerland) }\end{array}$ & $\begin{array}{l}\text { SC delivery of } 20 \mathrm{~mL} \text { at flexible flowrates using an infusion pump worn on belt or in } \\
\text { a belt-pouch } \\
\text { Commercialized }\end{array}$ & {$[62]$} \\
\hline $\begin{array}{l}\text { Libertas }^{\mathrm{TM}} \text { autoinjector (BD, Franklin Lakes, } \\
\text { NJ, USA) }\end{array}$ & SC delivery of $2-5 \mathrm{~mL}$ and $5-10 \mathrm{~mL}$ with viscosities up to $50 \mathrm{cP}$ & {$[66,68]$} \\
\hline Lapas $^{\circledR}$ patch pump (Bespak, King's Lynn, UK) & $\begin{array}{l}\text { Uses Bespak's Vapoursoft }{ }^{\circledR} \text { technology to deliver both viscous/non-viscous } \\
\text { formulations over a range of different volumes and delivery times }\end{array}$ & [69] \\
\hline $\begin{array}{l}\text { enFuse }{ }^{\circledR} \text { on-body platform (Enable Injections, } \\
\text { Cincinnati, OH, USA) }\end{array}$ & SC delivery of up to $50 \mathrm{~mL}$ with a prefilled or user-filled syringe & {$[70]$} \\
\hline $\begin{array}{l}\text { Wearable injectors (Sonceboz, Sonceboz- } \\
\text { Sombeval, Switzerland) }\end{array}$ & SC delivery of up to $20 \mathrm{~mL}$ of fluids up to $100 \mathrm{cP}$ at programmable dosing rate & {$[7 \mid]$} \\
\hline $\begin{array}{l}\text { Wearable injection devices (Sorrel Medical, } \\
\text { Netanya, Israel) }\end{array}$ & SC delivery of $3,5,10,20$, and $25 \mathrm{~mL}$ of high viscosity fluids & {$[72]$} \\
\hline DrugDeliverySystems (Weibel, Zug, Switzerland) & SC delivery of $25 \mathrm{~mL}$ of high viscosity fluids & {$[73]$} \\
\hline YpsoDose $^{\circledR}$ (Ypsomed, Burgdorf, Switzerland) & SC delivery of $2-10 \mathrm{~mL}$ of fluids with a range of viscosities & [74] \\
\hline
\end{tabular}

Abbreviation: OBDS, on-body delivery systems.

from $3.7 \mathrm{~mL}$ to $10 \mathrm{~mL} .{ }^{63}$ The CRONO ambulatory infusion pumps (Table 2) are currently approved for SC infusions for the treatment of thalassemia (deferoxamine), Parkinson's disease (apomorphine), and primary immunodeficiency (immunoglobulins). The Sensile Infusion Pump (Table 2) has recently launched in Europe for SC administration of treatment for advanced stages of Parkinson's disease. ${ }^{65}$

Other large-volume OBDS injection devices are currently in development (Table 2), including the BD Libertas $^{\mathrm{TM}}$ wearable autoinjector, which recently completed a clinical trial. ${ }^{66}$ Other devices are shown in Table 2, including the Lapas ${ }^{\circledR}$ patch pump, Enable Injections' enFuse ${ }^{\circledR}$ onbody platform, the Sonceboz wearable injectors, the Sorrell Medical wearable injection devices, Weibel's large-volume DrugDeliverySystems wearable platform, and Ypsomed's large-volume patch injector called YpsoDose ${ }^{\circledR}$.

\section{Technologies Exploiting SC Biology for the SC Delivery of Large-Volume Injectables}

Apart from technologies enabling high-concentration formulation development for biologics and the use of devices to inject large-volume doses via the SC route as discussed above, SC biology can be directly exploited to allow for the delivery of larger dose volumes. The enzyme hyaluronidase can be used to induce local and transient modification of the SC space through degradation of hyaluronan, which is a naturally occurring glycosaminoglycan found throughout the body that creates resistance to bulk fluid flow in the extracellular matrix and limits large-volume SC drug delivery. ${ }^{75}$ By degrading the hyaluronan at the local injection site, the hyaluronidase enables SC bulk fluid flow and facilitates the SC delivery of large volumes.

A purified recombinant human form of hyaluronidase (recombinant human hyaluronidase [rHuPH20]) has been commercially available in the US since 2005 (HYLENEX $^{\circledR}$ recombinant) and has been co-formulated with other therapeutic products using the ENHANZE $^{\circledR}$ drug delivery technology. ${ }^{76,77}$ ENHANZE $^{\circledR}$ has been shown to reduce dose administration time and dosing frequency, and enable the delivery of large volumes for rapid SC injections (5 to $15 \mathrm{~mL}$ ) and infusions (up to $600 \mathrm{~mL}$ ). ${ }^{14,78-80}$ ENHANZE $^{\circledR}$ may also potentially increase absorption and bioavailability of co-administered drugs, and decrease pharmacokinetic 
variability. ${ }^{81,82}$ This technology is used in several products approved in the US, Europe, and many other countries including trastuzumab (Herceptin Hylecta ${ }^{\mathrm{TM}}$ in the US, and Herceptin ${ }^{\circledR}$ SC outside the US), rituximab (RITUXAN HYCELA $^{\text {TM }}$ in the US, and MabThera ${ }^{\circledR}$ SC outside the US), ${ }^{77}$ HyQvia ${ }^{\circledR}$ (approved in the US and Europe for selfadministration of volumes of up to $600 \mathrm{~mL}$ in a single injection site), daratumumab (Darzalex Faspro ${ }^{\mathrm{TM}}$ in the US, ${ }^{83}$ DARZALEX ${ }^{\circledR}$ SC in Europe, ${ }^{84}$ and submitted for regulatory approval in $\operatorname{Japan}^{85}$ ), and a fixed-dose combination of pertuzumab and trastuzumab (Phesgo ${ }^{\mathrm{TM}}$ ) approved in the US. ${ }^{86}$ Additionally, there are a large number of investigational products in various stages of clinical development or regulatory review utilizing this technology. ${ }^{87}$

\section{Challenges and Gaps in High-Dosel Volume Drug Delivery, and Potential Solutions}

Significant progress has been made in facilitating SC injection for high-dose/volume biologics, with the development of technologies discussed above. These technologies include those that enable the formulation of high-dose /concentration SC injectables, devices that enable the SC administration of higher concentrations/viscosities or larger volumes of fluid, and those that modify the SC space to facilitate a larger volume of fluid to be administered. However, there are still several challenges that need to be overcome to exploit the full value of the $\mathrm{SC}$ route for the delivery of high-dose/volume injectables. In the SC Consortium's view, industry and clinical perspectives of traditional volume restrictions for SC injections $(\sim 1-2 \mathrm{~mL})$, as well as gaps in knowledge concerning large-volume/high-dose SC injection tolerability/pain and patient preferences (and the influence of various factors such as viscosity, and injection rate and location), are critical challenges that need to be addressed to advance the SC drug delivery space, along with raising awareness among patients, HCPs, and payers of the value of SC administration of such products.

By means of the aforementioned technologies, the preparation of stable high-concentration SC dosing solutions is feasible for many biotherapeutics. However, packaging these high-concentration (and often high-viscosity) formulations in a device can be challenging given the increased force required to administer the fluid within an acceptable injection time while meeting patient usability requirements. ${ }^{88}$ As discussed above, multiple designs for autoinjectors have been proposed to manage the increased injection force using a power source, such as a linear spring that provides extrusion force, torsion springs and regulators to control the application of force over time, the expansion of a compressed gas to replace spring force, or the use of electromechanical motors to minimize the impact on primary containers. Alternatively, the issue of increased force could be minimized by using a primary container that is strong enough to withstand the stresses generated by the power source used. These devices, however, may have limited volume capacities and increased complexity/cost relative to traditional autoinjectors which could limit their use.

As discussed in the previous sections, several technologies that deliver larger volumes of fluid ( $>3 \mathrm{~mL}$ ) are currently on the market, with many others in development. The availability of large-volume SC injection devices has traditionally been a limitation in delivering higher doses/larger volumes as prefilled syringes that are suitable for autoinjectors had a volume capacity of $1 \mathrm{~mL}$ and have only recently been available with a volume of $2.25 \mathrm{~mL}$. Additionally, containers that were suitable for use for on-body devices have previously been lacking, requiring the first commercial systems (eg, West SmartDose ${ }^{\circledR}$ ) to use a custom container. Largevolume SC injection devices could therefore help overcome the challenges during formulation development posed by the traditional injection volume limitation. It should however be recognized that self-injection user experience with these large-volume devices could be very different compared to self-injection with autoinjectors and prefilled syringes. In the Consortium's view, studies are needed to determine user preference for large-volume self-injection devices to better inform device designs and understand usability, impact on daily life, tolerability, and pain. Collaboration with primary packaging container, equipment suppliers, and innovative device manufacturers would also accelerate container and filling technology development for large-volume devices.

The perception of SC injections as painful and inconvenient poses a risk to adequate compliance with the treatment regimen, especially when the drug is intended for $\mathrm{SC}$ dosing in the home setting. Currently, public understanding of largevolume injection tolerability and pain, and the impact of various factors such as diffusion mechanism, viscosity, flow rate, and injection location, for SC injections of volumes above $3 \mathrm{~mL}$ are limited. ${ }^{89}$ Local injection site pain and irritation following SC injections can be due to a host of factors such as the needle insertion, composition of the formulation, volume administered, and injection site location. ${ }^{90-96}$ Minimizing pain and discomfort associated 
with SC injection is important to improve medication compliance and patient experience. ${ }^{97-101}$ However, injection site pain and discomfort associated with SC drug administration could be subjective and difficult to study. Some examples in the literature where studies were conducted include formulation changes, ${ }^{102-106}$ the administration at a preferred injection site, ${ }^{107}$ as well as a slowing down of the injection rate. ${ }^{93}$ If there is pain and irritation following SC injection, some patients may prefer the IV route despite the advantages of SC administration. Other reasons for IV preference include the desire for interaction with HCPs in a clinical setting and to avoid potential user errors for therapies administered on an infrequent basis. Quantifying the patient experience was identified as a key gap by the SC Consortium that can be addressed through collaborations between industry and academia. Improved scientific understanding of SC absorption of biologics at high doses and large volumes and the impact on pain is needed. Future studies on tolerability and pain associated with high-dose/large-volume self-injection devices should be tailored to the desired product profile and indication of interest to account for differences in user preferences and tolerability across patient populations, disease states/severity, and standards of care.

\section{Conclusion and Future Outlook}

SC delivery of biotherapeutics has demonstrated the ability to be well tolerated and effective, and may offer notable advantages as described above to patients and the healthcare system. Nevertheless, further progress is needed to address the gaps in knowledge and technology in the SC field to enable additional products that benefit patients to be developed. The SC Consortium, which was formed in 2018 in response to this need, highlights actionable issues in the SC industry, including in regards to the development of high-dose/volume SC technology as discussed in this article. The Consortium aims to strike up productive collaborations and partnerships between academia and industry in an effort to accelerate advances in the field. Potential partnership areas could include the development of preclinical models to predict SC bioavailability, thereby allowing for improved SC dosing regimens of high-dose/volume formulations and potentially resulting in faster adoption and increased switching from IV to SC. Additional details for an open innovation challenge to scientists in academia and industry from the SC Consortium to help to close this gap in SC bioavailability are published separately. ${ }^{108}$ These academicindustry partnerships could help standardize approaches to investigating the human SC space, and improve our understanding and prioritize critical parameters that directly affect clinical outcomes. Other potential partnership areas include the development of tools to assess injection-related tissue responses (eg, injection pain); and studying the impacts of self-injection on the patient experience, clinical outcomes, and user-centered design.

\section{Highlights}

- Subcutaneous delivery of biologics has previously been limited by injection volume

- Available technologies facilitate subcutaneous delivery of higher doses/volumes

- High-dose biologics can be formulated/delivered as high-concentration injectables

- Alternatively, high-dose biologics can be injected subcutaneously in larger volumes

- These technologies, as well as critical knowledge gaps/ challenges, are discussed

\section{Acknowledgments}

The authors thank the following contributors for their critical review of the manuscript: Deep Bhattacharya (Pfizer), Paolo Mangiagalli (Sanofi), Maria-Teresa Peracchia (Sanofi), Vinay Radhakrishnan (Pfizer), Ronak Shah (Bristol-Myers Squibb), and Lionel Vedrine (Sanofi).

SC Consortium members: Jennie Stevenson (Amgen), Donna French (AstraZeneca), Shawn Davis (AstraZeneca), Rajesh Gandhi (Bristol-Myers Squibb), Neil Mathias (Bristol-Myers Squibb), David Collins (Eli Lilly and Company), Kathleen Lin (Eli Lilly and Company), Michael LaBarre (Halozyme), Ketan Amin (Johnson \& Johnson), Ronald Smith (Merck), Sachin Mittal (Merck), Manuel Sánchez-Félix (Novartis), Joerg Nerkamp (Novartis), Advait Badkar (Pfizer), Matt Burke (Radius Health), Maria-Teresa Peracchia (Sanofi), Lionel Vedrine (Sanofi).

Medical writing support, including assisting authors with the development of the manuscript drafts and incorporation of comments, was provided by Grace Jeong, PhD of Alphabet Health (New York, NY), supported by the SC Consortium, according to Good Publication Practice guidelines (https://www.ismpp.org/gpp3).

\section{Disclosure}

Advait V Badkar is an employee and stockholder of Pfizer. Rajesh B Gandhi is an employee and stockholder of Bristol-Myers Squibb. Shawn Davis is an employee and 
stockholder of AstraZeneca. Michael $\mathrm{J}$ LaBarre is an employee and stockholder of Halozyme Therapeutics, Inc. The authors report no other potential conflicts of interest for this work.

\section{References}

1. Andrews L, Ralston S, Blomme E, Barnhart K. A snapshot of biologic drug development: challenges and opportunities. Hum Exp Toxicol. 2015;34(12):1279-1285. doi:10.1177/09603271 15603594

2. Anselmo AC, Gokarn Y, Mitragotri S. Non-invasive delivery strategies for biologics. Nat Rev Drug Discov. 2019;18 (1):19-40. doi:10.1038/nrd.2018.183

3. Anderson D, Liu R, Anand Subramony J, Cammack J. Design control considerations for biologic-device combination products. Adv Drug Deliv Rev. 2017;112:101-105. doi:10.1016/j. addr.2017.01.003

4. Chung SW, Hil-lal TA, Byun Y. Strategies for non-invasive delivery of biologics. $J$ Drug Target. 2012;20(6):481-501. doi:10.3109/1061186X.2012.693499

5. US Food and Drug Administration. Patient-focused drug development: collecting comprehensive and representative input guidance for industry, food and drug administration staff, and other stakeholders. Available from: https://www.fda.gov/regulatoryinformation/search-fda-guidance-documents/patient-focused-drug -development-collecting-comprehensive-and-representative-input. Accessed March 16, 2020.

6. Rule S, Briones J, Smith R, et al. Preference for rituximab subcutaneous (Sc) and intravenous (Iv) among patients with $\mathrm{Cd} 20+$ non-Hodgkin's lymphoma ( $\mathrm{Nhl}$ ) completing the rasq measure in randomized phase III studies prefmab and mabcute. Value Health. 2014;17(7):A537. doi:10.1016/j.jval.2014.08.1719

7. Stoner KL, Harder H, Fallowfield LJ, Jenkins VA. Intravenous versus subcutaneous drug administration. which do patients prefer? A systematic review. Patient. 2014. doi:10.1007/s40271-0140075-y

8. Fallowfield L, Osborne S, Langridge C, Monson K, Kilkerr J, Jenkins V. Implications of subcutaneous or intravenous delivery of trastuzumab; further insight from patient interviews in the PrefHer study. Breast. 2015;24(2):166-170. doi:10.1016/j. breast.2015.01.002

9. Jackisch C, Muller V, Dall P, et al. Subcutaneous trastuzumab for HER2-positive breast cancer - evidence and practical experience in 7 german centers. Geburtshilfe Frauenheilkd. 2015;75 (6):566-573. doi:10.1055/s-0035-1546172

10. Pivot X, Gligorov J, Muller V, et al. Preference for subcutaneous or intravenous administration of trastuzumab in patients with HER2-positive early breast cancer (PrefHer): an open-label randomised study. Lancet Oncol. 2013;14(10):962-970. doi:10.1016/ S1470-2045(13)70383-8

11. Turner MR, Balu-Iyer SV. Challenges and opportunities for the subcutaneous delivery of therapeutic proteins. J Pharm Sci. 2018;107(5):1247-1260. doi:10.1016/j.xphs.2018.01.007

12. Walsh CA, Minnock P, Slattery C, et al. Quality of life and economic impact of switching from established infliximab therapy to adalimumab in patients with rheumatoid arthritis. Rheumatology (Oxford). 2007;46(7):1148-1152. doi:10.1093/ rheumatology/kem074

13. Hedayati E, Fracheboud L, Srikant V, Greber D, Wallberg S, Linder Stragliotto C. Economic benefits of subcutaneous trastuzumab administration: a single institutional study from Karolinska university hospital in Sweden. PLoS One. 2019;14 (2):e0211783. doi:10.1371/journal.pone.0211783
14. Martin A, Lavoie L, Goetghebeur M, Schellenberg R. Economic benefits of subcutaneous rapid push versus intravenous immunoglobulin infusion therapy in adult patients with primary immune deficiency. Transfus Med. 2013;23(1):55-60. doi:10.1111/j.13653148.2012.01201.x

15. Rule S, Collins GP, Samanta K. Subcutaneous vs intravenous rituximab in patients with non-hodgkin lymphoma: a time and motion study in the United Kingdom. J Med Econ. 2014;17 (7):459-468. doi:10.3111/13696998.2014.914033

16. North RT, Harvey VJ, Cox LC, Ryan SN. Medical resource utilization for administration of trastuzumab in a New Zealand oncology outpatient setting: a time and motion study. Clinicoecon Outcomes Res. 2015;7:423-430. doi:10.2147/CEOR.S85599

17. Papadmitriou K, Trinh XB, Altintas S, Van Dam PA, Huizing MT, Tjalma WA. The socio-economical impact of intravenous (IV) versus subcutaneous (SC) administration of trastuzumab: future prospectives. Facts Views Vis Obgyn. 2015;7(3):176-180.

18. Wu N, Bhurke S, Shah N, Harrison DJ. Application of a validated algorithm to estimate the effectiveness and cost of biologics for rheumatoid arthritis in the US pharmacy benefit manager context. Clinicoecon Outcomes Res. 2015;7:257-266. doi:10.2147/CEOR.S83932

19. Kyriopoulos D, Tsiantou V, Papageorgiou L, Theodoropoulou F, Athanasakis $\mathrm{K}$. Cost-minimization and budget impact analysis of rituximab SC VS rituximab IV for non-hodgkin's lymphoma (NHLs) in Greece. J Cancer Ther. 2017;8(8):726-734. doi:10.4236/ jct.2017.88063

20. Mateos M-V, Nahi H, Legiec W, et al. Efficacy and safety of the randomized, open-label, non-inferiority, phase 3 study of subcutaneous (SC) versus intravenous (IV) daratumumab (DARA) administration in patients (pts) with relapsed or refractory multiple myeloma (RRMM): COLUMBA. J Clin Oncol. 2019;37 (15_suppl):8005. doi:10.1200/JCO.2019.37.15_suppl.8005

21. Chari A, Goldschmidt H, San-Miguel J, et al. Subcutaneous (SC) daratumumab (DARA) in combination with standard multiple myeloma (MM) treatment regimens: an open-label, multicenter phase 2 study (PLEIADES). Clin Lymphoma Myeloma Leuk. 2019;19(10):e16-e17. doi:10.1016/j. clml.2019.09.023

22. Usmani SZ, Nahi H, Mateos MV, et al. Subcutaneous delivery of daratumumab in relapsed or refractory multiple myeloma. Blood. 2019;134(8):668-677. doi:10.1182/blood.2019000667

23. Jin X, Zhu DD, Chen BZ, Ashfaq M, Guo XD. Insulin delivery systems combined with microneedle technology. Adv Drug Deliv Rev. 2018;127:119-137. doi:10.1016/j.addr.2018.03.011

24. Hao Feng Y, Ling Liu J, Zhu DD, Hao YY, Dong Guo X. Multiscale simulations of drug distributions in polymer dissolvable microneedles. Colloids Surf B Biointerfaces. 2020;189:110844. doi:10.1016/j.colsurfb.2020.110844

25. Chen BZ, Zhang LQ, Xia YY, Zhang XP, Guo XD. A basal-bolus insulin regimen integrated microneedle patch for intraday postprandial glucose control. Sci Adv. 2020;6(28):eaba7260. doi:10.1126/sciadv.aba7260

26. Barolet D, Benohanian A. Current trends in needle-free jet injection: an update. Clin Cosmet Investig Dermatol. 2018;11:231-238. doi:10.2147/CCID.S162724

27. Pons-Faudoa FP, Ballerini A, Sakamoto J, Grattoni A. Advanced implantable drug delivery technologies: transforming the clinical landscape of therapeutics for chronic diseases. Biomed Microdevices. 2019;21(2):47. doi:10.1007/s10544-019-0389-6

28. Collins DS, Sanchez-Felix M, Badkar AV, Mrsny R. Accelerating the development of novel technologies and tools for the subcutaneous delivery of biotherapeutics. $J$ Control Release. 2020;321:475-482. doi:10.1016/j.jconrel.2020.02.036

29. Amgen. Repatha ${ }^{\circledR}$ (evolocumab). Available from: https://www. repatha.com/how-to-start-repatha-injection/. Accessed October 10, 2019. 
30. Frost GI. Recombinant human hyaluronidase (rHuPH20): an enabling platform for subcutaneous drug and fluid administration. Expert Opin Drug Deliv. 2007;4(4):427-440. doi:10.1517/17425247.4.4.427

31. Mathaes R, Koulov A, Joerg S, Mahler HC. Subcutaneous injection volume of biopharmaceuticals-pushing the boundaries. J Pharm Sci. 2016;105(8):2255-2259. doi:10.1016/j.xphs.2016.05.029

32. Palm T, Sahin E, Gandhi R, Khossravi M. The Importance of the Concentration-Temperature-Viscosity Relationship for the Development of Biologics. BioProcess International; 2015.

33. Garidel P, Kuhn AB, Schafer LV, Karow-Zwick AR, Blech M. High-concentration protein formulations: how high is high? Eur $J$ Pharm Biopharm. 2017;119:353-360. doi:10.1016/j. ejpb.2017.06.029

34. Johnson B, Rostovtsev A. High concentration biologic formulations: challenges and solutions. Drug Discov Devel. 2017.

35. Wang W, Singh S, Zeng DL, King K, Nema S. Antibody structure, instability, and formulation. J Pharm Sci. 2007;96(1):1-26. doi:10.1002/jps.20727

36. Warne NW. Development of high concentration protein biopharmaceuticals: the use of platform approaches in formulation development. Eur J Pharm Biopharm. 2011;78(2):208-212. doi:10.1016/j.ejpb.2011.03.004

37. Arecor. Our portfolio; 2020. Available from: http://arecor.com/ $\mathrm{p}^{\wedge}$ roducts/. Accessed June 11, 2020.

38. Adocia. BIOCHAPERONE ${ }^{\circledR}$ LISPRO; 2020. Available from: https://www.adocia.com/products/biochaperone-ultra-fast-analoginsulin/. Accessed March 16, 2020.

39. ExcelseBio. Your medicine, transformed; 2020. http://www.excel sebio.com/partnering. Accessed March 27, 2020.

40. Xeris Pharmaceuticals. The Xeris solution for conventional formulation limitations. Available from: https://www.xerispharma.com/ research-development/technology. Accessed August 31, 2020.

41. Elektrofi. Redefining the delivery of biologics; 2020. Available from: https://www.elektrofi.com/welcome\#technology. Accessed August 31, 2020.

42. Lindy Biosciences. Microglassification ${ }^{\mathrm{TM}}$. Available from: https:// www.lindybio.com/technology. Accessed August 31, 2020.

43. Althea's new drug formulation technology gains attention from two more top pharmaceutical companies; 2015. Available from: https://ajibio-pharma.com/news-post/altheas-new-drugformulation-technology-gains-attention-from-two-more-toppharmaceutical-companies/. Accessed August 31, 2020.

44. Arecor. What we do. Available from: http://arecor.com/technol ogy/. Accessed August 31, 2020.

45. Adocia. BioChaperone ${ }^{\circledR}$. Available from: https://www.adocia. com/technology/biochaperone-technology-2/. Accessed August 31, 2020.

46. ExcelseBio. EXCELSETM formulation technology. Available from: http://www.excelsebio.com/technology. Accessed August 31, 2020.

47. Nemera. Safelia ${ }^{\circledR}$ autoinjector designed to be patients and syringes friendly; 2020. Available from: https://www.nemera.net/wpcontent/uploads/2014/06/Nemera_LEAFLET-

Safelia_revJune2016.pdf. Accessed August 31, 2020.

48. Owen Mumford Pharmaceutical Services. Autoject ${ }^{\circledR}$ Visco a disposable auto-injector developed for high viscosity formulations; 2020. Available from: https://www.ompharmaservices.com/ wp-content/uploads/2019/09/Autoject-Visco-Case-Study-OwenMumford.pdf. Accessed August 31, 2020.

49. Owen Mumford Pharmaceutical Services. Autoject ${ }^{\circledR}$ visco; 2020. Available from: https://www.ompharmaservices.com/productportfolio/autoject-visco/. Accessed August 31, 2020.

50. Ypsomed. YpsoMate 2.25 - the 2-step large volume autoinjector. Available from: https://yds.ypsomed.com/en/injectionsystems/auto-injectors/ypsomate-2-25.html. Accessed August 31, 2020.
51. SHL Group. Rotaject ${ }^{\circledR}$ technology; 2020. Available from: https:// www.shl.group/products-and-services/rotaject-technology-autoinjector/. Accessed August 31, 2020.

52. Bespak. Vapoursoft ${ }^{\circledR}$ powered auto-injectors; 2020. Available from: https://bespak.com/products/injection-devices/vapoursoftpowered-auto-injectors/. Accessed August 31, 2020.

53. Collier DH, Bitman B, Coles A, Liu L, Kumar S, Judd C. A novel electromechanical autoinjector, AutoTouch, for self-injection of etanercept: real-world use and benefits. Postgrad Med. 2017;129 (1):118-125. doi:10.1080/00325481.2017.1251291

54. Amgen launches the ENBREL Mini ${ }^{\mathrm{TM}}$ single-dose prefilled cartridge with AutoTouch ${ }^{\mathrm{TM}}$ reusable autoinjector that is ergonomically designed for patients; 2017. Available from: https://www. amgen.com/media/news-releases/2017/11/amgen-launches-theenbrel-mini-single-dose-prefilled-cartridge-with-autotouchreusable-autoinjector-that-is-ergonomically-designed-for-patients /. Accessed August 31, 2020.

55. Oval Medical Technologies. $\operatorname{ArQ}^{\circledR}$-bios subcutaneous (high viscosities and/or high volumes); 2020. Available from: https://www.ovalmedical.com/portfolio/arq-bios/. Accessed August 31, 2020.

56. Veilleux JC, Shepherd JE. Pressure and stress transients in autoinjector devices. Drug Deliv Transl Res. 2018;8(5):1238-1253. doi:10.1007/s13346-018-0568-7

57. Teva launches AJOVY for the treatment of migraine with the YpsoMate autoinjector from Ypsomed; 2020. Available from: https://www.ypsomed.com/fr-FR/dernieres-nouvelles-detail/tevalaunches-ajovy-for-the-treatment-of-migraine-with-the-ypsomateautoinjector-from-ypsomed.html. Accessed July 21, 2020.

58. World Pharmaceutical Frontiers. Latest in injectable technology to enhance biologic development. Available from: http://www. worldpharmaceuticals.net/contractors/world-pharmaceuticalfrontiers/latest-in-injectable-technology-to-enhance-biologicdevelopment/. Accessed April 15, 2020.

59. Burton L, Ying W, Kulshrestha A, Gandhi RB. Challenges in Subcutaneous Product Development of Biologics-Understanding the Impact of Solution Viscosity and Potential Strategies for Enabling SC Delivery of High-Dose And/Or Viscous Biotherapeutics. 2017.

60. Yadi K, Maritan L. Autoinjector platform - identifying new, enhanced device delivery solutions for chronic diseases. Drug Dev Deliv. 2020.

61. Canè Medical Technology. Infusion pumps. Available from: http://www.infusionpump.it/category/infusion-pumps/. Accessed August 31, 2020.

62. Sensile Medical. Launched products. Available from: https://www. sensile-medical.com/products.html. Accessed August 31, 2020.

63. West Pharma. West SmartDose drug delivery platform. Available from: https://www.westpharma.com/products/self-injectionplatforms/smartdose. Accessed June 11, 2020.

64. Alexion. Investor day. Available from: https://iralexion.com/staticfiles/46d4f73c-371a-402d-a271-936d0283b3f6. Accessed October 24, 2019.

65. Sensile Medical. Innovative micro-infusion pump from gerresheimer subsidiary sensile medical developed and successfully launched for EVER pharma. Available from: https://www.sensile-medical. com/fileadmin/user_upload/News_Events/2019/20190703_Gx_ PM_LAUNCH_Mikropumpe_SEN_e.pdf. Accessed March 17, 2020.

66. BD Completes Clinical Trial for BD Libertas ${ }^{\mathrm{TM}}$ wearable injector; 2020. Available from: https://www.bd.com/en-us/company/newsand-media/press-releases/bd-completes-clinical-trial-for-bdlibertas-wearable-injector. Accessed June 11, 2020.

67. West Pharma. SmartDose ${ }^{\circledR} 3.5$ injector. Available from: https:// www.westpharma.com/products/self-injection-platforms/smart dose/smartdose-3-5. Accessed August 31, 2020. 
68. BD. BD Libertas ${ }^{\mathrm{TM}}$ wearable autoinjector. Available from: https:// drugdeliverysystems.bd.com/products/self-injection-systems/liber tas-wearable-autoinjector. Accessed 31 August 2020.

69. Bespak. Lapas $^{\circledR}$ : an innovative patch pump device powered by VapourSoft $^{\circledR}$. Available from: https://bespak.com/services/innova tion/patch-pump-lapas/. Accessed August 31, 2020.

70. Enable Injections. The enable enFuse ${ }^{\circledR}$ on-body platform. Available from: https://enableinjections.com/technology/enfuseon-body-platform/. Accessed August 31, 2020.

71. Sonceboz. Sonceboz wearable injectors. Available from: https:// www.sonceboz.com/wearable-injectors. Accessed August 31, 2020.

72. Sorrel Medical. Platform. Available from: https://www.sorrelme dical.com/platform/. Accessed August 31, 2020

73. Weibel CDS AG. DrugDeliverySystems. Available from: https://wei belcds.com/products/drug-delivery-systems/. Accessed August 31, 2020.

74. Ypsomed. YpsoDose - the large volume patch injector. Available from: https://yds.ypsomed.com/en/injection-systems/ypsodose. html. Accessed August 31, 2020.

75. Atkinson WS. Use of hyaluronidase with local anesthesia in ophthalmology; preliminary report. Arch Ophthalmol. 1949;42 (5):628-633. doi:10.1001/archopht.1949.00900050638012

76. Halozyme. Removing traditional limitations on administering therapies: ENHANZE drug delivery technology. Available from: https://www.halozyme.com/enhanze/overview/default.aspx. Accessed October 10, 2019.

77. Locke KW, Maneval DC, LaBarre MJ. ENHANZE((R)) drug delivery technology: a novel approach to subcutaneous administration using recombinant human hyaluronidase PH20. Drug Deliv. 2019;26(1):98-106. doi:10.1080/ 10717544.2018.1551442

78. Pivot X, Gligorov J, Muller V, et al. Patients' preferences for subcutaneous trastuzumab versus conventional intravenous infusion for the adjuvant treatment of HER2-positive early breast cancer: final analysis of 488 patients in the international, randomized, two-cohort PrefHer study. Ann Oncol. 2014;25 (10):1979-1987. doi:10.1093/annonc/mdu364

79. Rummel M, Kim TM, Aversa F, et al. Preference for subcutaneous or intravenous administration of rituximab among patients with untreated CD20+ diffuse large B-cell lymphoma or follicular lymphoma: results from a prospective, randomized, open-label, crossover study (PrefMab). Ann Oncol. 2017;28(4):836-842. doi:10.1093/annonc/mdw685

80. Ponsford M, Carne E, Kingdon C, et al. Facilitated subcutaneous immunoglobulin (fSCIg) therapy-practical considerations. Clin Exp Immunol. 2015;182(3):302-313. doi:10.1111/ cei. 12694

81. Morcos PN, Zhang X, McIntyre C, Bittner B, Rowell L, Hussain Z. Pharmacokinetics and pharmacodynamics of single subcutaneous doses of tocilizumab administered with or without rHuPH20. Int J Clin Pharmacol Ther. 2013;51(7):537-548. doi:10.5414/CP201847

82. Morrow L, Muchmore DB, Ludington EA, Vaughn DE, Hompesch M. Reduction in intrasubject variability in the pharmacokinetic response to insulin after subcutaneous co-administration with recombinant human hyaluronidase in healthy volunteers. Diabetes Technol Ther. 2011;13 (10):1039-1045. doi:10.1089/dia.2011.0115

83. Halozyme announces janssen receives FDA approval of DARZALEX FASPROTM ${ }^{\text {TM }}$ utizing halozyme's ENHANZE ${ }^{\circledR}$ technology for the treatment of patients with multiple myeloma; 2020. Available from: https://www.halozyme.com/investors/newsreleases/news-release-details/2020/Halozyme-Announces-Janssen -Receives-FDA-Approval-Of-DARZALEX-FASPRO-UtilizingHalozymes-ENHANZE-Technology-For-The-Treatment-OfPatients-With-Multiple-Myeloma/default.aspx. Accessed May 14, 2020 .
84. Halozyme announces janssen receives european marketing authorization for subcutaneous DARZALEX ${ }^{\circledR}$ utilizing halozyme's ENHANZE $^{\circledR}$ technology for the treatment of patients with multiple myeloma; 2020. Available from: https://www.halozyme.com/inves tors/news-releases/news-release-details/2020/Halozyme-AnnouncesJanssen-Receives-European-Marketing-Authorization-For-Subcuta neous-DARZALEX-Utilizing-Halozymes-ENHANZE-TechnologyFor-The-Treatment-Of-Patients-With-Multiple-Myeloma/default. aspx. Accessed May 14, 2020.

85. Halozyme announces janssen submits new drug application in japan for daratumumab subcutaneous formulation utilizing halozyme's ENHANZE $^{\circledR}$ technology for patients with multiple myeloma; 2020. Available from: https://www.halozyme.com/investors/news-releases /news-release-details/2020/Halozyme-Announces-Janssen-SubmitsNew-Drug-Application-In-Japan-For-Daratumumab-SubcutaneousFormulation-Utilizing-Halozymes-ENHANZE-Technology-For-Pati ents-With-Multiple-Myeloma/default.aspx. Accessed May 14, 2020.

86. Halozyme announces roche receives FDA approval for Phesgo ${ }^{\mathrm{TM}}$ (fixed-dose combination of Perjeta ${ }^{\circledR}$ and Herceptin ${ }^{\circledR}$ for subcutaneous injection) utilizing halozyme's ENHANZE ${ }^{\circledR}$ technology for the treatment of patients with HER2-positive breast cancer; 2020. Available from: https://www.halozyme.com/investors/newsreleases/news-release-details/2020/Halozyme-Announces-RocheReceives-FDA-Approval-For-Phesgo-Fixed-Dose-CombinationOf-Perjeta-And-Herceptin-For-Subcutaneous-Injection-UtilizingHalozymes-ENHANZE-Technology-For-The-Treatment-Of-Pati ents-With-HER2-Positive-Breast-Cancer/default.aspx. Accessed July 21, 2020.

87. Halozyme. Broad range of partnered and proprietary products; 2020. Available from: https://www.halozyme.com/enhanze/pipe line/default.aspx. Accessed March 17, 2020.

88. Jansen P. 2014 to 2018: An Update on the State of Wearable Injectors. ONdrugDelivery Magazine; 2018:6-8.

89. Sirkar R. Evaluating Formulation and Device Factors on Subcutaneous Administration. 2019.

90. Jones GB, Collins DS, Harrison MW, Thyagarajapuram NR, Wright JM. Subcutaneous drug delivery: an evolving enterprise. Sci Transl Med. 2017;9(405):eaaf9166. doi:10.1126/scitranslmed. aaf9166

91. Zijlstra E, Jahnke J, Fischer A, Kapitza C, Forst T. Impact of injection speed, volume, and site on pain sensation. J Diabetes Sci Technol. 2018;12(1):163-168. doi:10.1177/ 1932296817735121

92. Hamuro L, Kijanka G, Kinderman F, et al. Perspectives on subcutaneous route of administration as an immunogenicity risk factor for therapeutic proteins. $J$ Pharm Sci. 2017;106 (10):2946-2954. doi:10.1016/j.xphs.2017.05.030

93. Dias C, Abosaleem B, Crispino C, Gao B, Shaywitz A. Tolerability of high-volume subcutaneous injections of a viscous placebo buffer: a randomized, crossover study in healthy subjects. AAPS PharmSciTech. 2015;16(5):1101-1107. doi:10.1208/s12249-0150288-y

94. Doughty DV, Clawson CZ, Lambert W, Subramony JA. Understanding subcutaneous tissue pressure for engineering injection devices for large-volume protein delivery. J Pharm Sci. 2016;105(7):2105-2113. doi:10.1016/j.xphs.2016.04.009

95. Berteau C, Filipe-Santos O, Wang T, Rojas HE, Granger C, Schwarzenbach F. Evaluation of the impact of viscosity, injection volume, and injection flow rate on subcutaneous injection tolerance. Med Devices (Auckl). 2015;8:473-484. doi:10.2147/ MDER.S91019

96. Mercadante S, Ferrera P, Girelli D, Patients' CA. Relatives' perceptions about intravenous and subcutaneous hydration. J Pain Symptom Manage. 2005;30(4):354-358. doi:10.1016/j. jpainsymman.2005.04.004 
97. Schiff M, Saunderson S, Mountian I, Hartley P. Chronic disease and self-injection: ethnographic investigations into the patient experience during treatment. Rheumatol Ther. 2017;4 (2):445-463. doi:10.1007/s40744-017-0080-4

98. Baxter AL, Cohen LL, Burton M, Mohammed A, Lawson ML. The number of injected same-day preschool vaccines relates to preadolescent needle fear and HPV uptake. Vaccine. 2017;35 (33):4213-4219. doi:10.1016/j.vaccine.2017.06.029

99. Sokolowski CJ, Giovannitti JA Jr., Boynes SG. Needle phobia: etiology, adverse consequences, and patient management. Dent Clin North Am. 2010;54(4):731-744. doi:10.1016/j. cden.2010.06.012

100. Gedney JJ, Logan H. Perceived control and negative affect predict expected and experienced acute clinical pain: a structural modeling analysis. Clin J Pain. 2007;23(1):35-44. doi:10.1097/ 01.ajp.0000210940.04182.a3

101. Gely C, Marin L, Gordillo J, et al. N032 impact of pain due to subcutaneous administration of a biological drug. J Crohns Colitis. 2018;12(supplement_1):S582-S583. doi:10.1093/eccojcc/jjx 180.1046

102. Cohen S, Samad A, Karis E, et al. Decreased injection site pain associated with phosphate-free etanercept formulation in rheumatoid arthritis or psoriatic arthritis patients: a randomized controlled trial. Rheumatol Ther. 2019;6(2):245-254. doi:10.1007/ s40744-019-0152-8
103. Laursen T, Hansen B, Fisker S. Pain perception after subcutaneous injections of media containing different buffers. Basic Clin Pharmacol Toxicol. 2006;98(2):218-221. doi:10.1111/j.17427843.2006.pto_271.x

104. Frenken LA, van Lier HJ, Jordans JG, et al. Identification of the component part in an epoetin alfa preparation that causes pain after subcutaneous injection. Am J Kidney Dis. 1993;22 (4):553-556. doi:10.1016/s0272-6386(12)80928-0

105. Yu AW, Leung CB, Li PK, Lui SF, Lai KN. Pain perception following subcutaneous injections of citrate-buffered and phosphate-buffered epoetin alpha. Int J Artif Organs. 1998;21 (6):341-343. doi:10.1177/039139889802100612

106. Nash P, Vanhoof J, Hall S, et al. Randomized crossover comparison of injection site pain with $40 \mathrm{mg} / 0.4$ or $0.8 \mathrm{~mL}$ formulations of adalimumab in patients with rheumatoid arthritis. Rheumatol Ther. 2016;3(2):257-270. doi:10.1007/s40744-016-0041-3

107. Martin JR, Beegle NL, Zhu Y, Hanisch EM. Subcutaneous administration of bortezomib: a pilot survey of oncology nurses. $J A d v$ Pract Oncol. 2015;6(4):308-318. doi:10.6004/jadpro.2015.6.4.2

108. Sanchez-Felix M, Burke M, Chen HH, Patterson C, Mittal S. Predicting bioavailability of monoclonal antibodies after subcutaneous administration: open innovation challenge. Adv Drug Deliv Rev. 2020;167:66-77. doi:10.1016/j.addr.2020.05.009

\section{Publish your work in this journal}

Drug Design, Development and Therapy is an international, peerreviewed open-access journal that spans the spectrum of drug design and development through to clinical applications. Clinical outcomes, patient safety, and programs for the development and effective, safe, and sustained use of medicines are a feature of the journal, which has also been accepted for indexing on PubMed Central. The manuscript management system is completely online and includes a very quick and fair peer-review system, which is all easy to use. Visit http://www. dovepress.com/testimonials.php to read real quotes from published authors. 